\title{
Asbestos bodies in the sputum of asbestos workers: correlation with occupational exposure
}

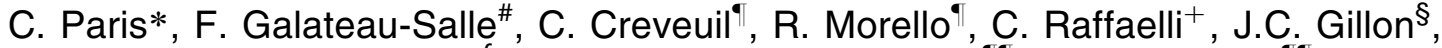 \\ M.A. Billon-Galland ${ }^{f}$, J.C. Pairon**, L. Chevreau" ${ }^{*}$, M. Letourneux
}

Asbestos bodies in the sputum of asbestos workers: correlation with occupational exposure. C. Paris, F. Galateau-Salle, C. Creveuil, R. Morello, C. Raffaelli, J.C. Gillon, M.A. Billon-Galland, J.C. Pairon, L. Chevreau, M. Letourneux. (C)ERS Journals Ltd 2002.

ABSTRACT: A cross-sectional medical survey including collection of three consecutive sputum samples was carried out among 270 retired workers of a textile and friction materials factory, in order to investigate the relationship between asbestos body identification and asbestos exposure.

The individual cumulative asbestos exposure, determined by means of a plant-specific job-exposure matrix based on asbestos air measurements in the workshops, proved to be heavy with a mean cumulative exposure of $217 \mathrm{fibres} \cdot \mathrm{mL}^{-1} \times \mathrm{yr}$. Macrophages and asbestos bodies were identified in sputum samples by light microscopy.

The lung origin of the sputum, suggested by the presence of macrophages and/or asbestos bodies, was confirmed in $82.6 \%$ of subjects, and $53 \%$ of these samples were positive for asbestos bodies. The prevalence of asbestos bodies was not related to sex, smoking status or latency. Conversely, multivariate analysis showed a positive relationship with cumulative exposure, duration and intensity of exposure to asbestos, as well as age and time since retirement.

These findings suggest that sputum analysis for asbestos bodies may remain a relevant and noninvasive marker of heavy occupational exposure to asbestos, even years after retirement. Owing to the new perspectives in lung cancer screening, it might contribute to the identification of high-risk subjects.

Eur Respir J 2002; 20: 1167-1173.

\begin{abstract}
* Occupational Disease Dept, Rouen University Hospital, Rouen, "Pathology Dept and Medical Computing Laboratory, Caen University Hospital, Caen, ${ }^{+}$GISTAF, Occupational Health Service, Condé sur Noireau, ${ }^{\text {S}}$ Pneumology Dept, J. Monod Hospital, Flers, ${ }^{f}$ Laboratory of Inhaled Particles Study, Paris, **EPI 99-09, University of Medicine, Créteil, and "Occupational Health Institute of Lower-Normandy, University of Medicine, Caen, France.
\end{abstract}

Correspondence: C. Paris, Service de Médecine du Travail, CHU de Rouen 76031, Rouen cedex, France. Fax: 33232888184

E-mail: christophe.paris@chu-rouen.fr

Keywords: Asbestos bodies, occupational exposure, sputum

Received: July 192001

Accepted after revision: May 162002

This study was supported by the Caisse Régionale d'Assurance Maladie de Normandie.
Quantitative and qualitative information on asbestos exposure is an important criterion for the diagnosis and compensation of asbestos-related diseases. It may also be relevant to the identification of groups at high risk of lung cancer, who could benefit from new progress in screening programmes [1-2]. Occupational questionnaires and the use of a job-exposure matrix are not sufficiently accurate in all cases, which is why attention has turned to asbestos-body quantification in biological samples. In comparison with bronchoalveolar lavage, thoracoscopic or open lung biopsy, induced sputum has the obvious advantage of being a noninvasive method. Unfortunately, the sensitivity of asbestos bodies in sputum as a marker of asbestos exposure is poor, whereas a sputum sample positive for asbestos bodies suggests a significant lung asbestos burden [3]. The objective of this investigation, conducted in a population of retired workers from a plant manufacturing asbestos-containing products (textile and friction materials), was to study the correlation between the presence of asbestos bodies in the sputum of these subjects and the amount and mineralogical type of their asbestos exposure.

\section{Methods}

\section{Subjects}

A total of 270 retired workers from an asbestos textile and friction material factory were included in a medical surveillance programme organised for retired asbestos workers in the hospitals of Caen and Flers (Normandy, France).

Chrysotile was the only type of asbestos used in the friction material workshops (manufacture of brake and clutch linings from asbestos fibres and formophenolic resins), while chrysotile and a smaller amount of crocidolite $(20 \%)$ were both used in several textile workshops (manufacture of insulation materials: textiles, pads, tapes).

None of these subjects declared any contact with 
asbestos apart from their occupational exposure in this factory.

\section{Sputum collection}

The first sputum sample was collected at the end of the medical check-up, after inhalation of an isotonic saline aerosol generated by an ultrasonic nebuliser for $10 \mathrm{~min}$ and a short expiratory physiotherapy, in a carefully cleaned flask containing $10 \mathrm{~mL}$ of $10 \%$ formalin, previously filtered through a membrane filter (Millipore ( $0.45 \mu \mathrm{m}$ pore size; Prolabo, Paris, France). It was divided into two samples, one for cytological analysis and the other for mineralogical analysis.

A morning sputum sample was collected at home by each subject over the next 2 days in two different flasks cleaned and prepared with $10 \%$ formalin in a similar way, for mineralogical analysis.

\section{Cytological analysis}

The sputum samples collected for cytological analysis were homogenised by metal-pin vortex for $10 \mathrm{~min}$, and then centrifuged at $724.5 \times \mathrm{g}$ for $10 \mathrm{~min}$ at $4{ }^{\circ} \mathrm{C}$.

Four smears were prepared from the pellet and were stained according to the Papanicolaou technique. The slides were then screened for macrophages by light microscopy ( $\times 25$ magnification).

All slides were viewed by the same investigator.

\section{Mineralogical analysis}

The sputum sample was allowed to react at room temperature for $1-2 \mathrm{~h}$ with $20 \mathrm{~mL}$ of freshly filtered sodium hypochlorite (commercial laundry bleach) with gentle shaking until complete digestion of the organic material.

The suspension was filtered through a membrane filter (Millipore $\mathbb{R}$ ) $0.45 \mu \mathrm{m}$ pore size; Prolabo), and the membrane was washed (five times with distilled water) and dehydrated using isopropyl alcohol (Prolabo). The membrane was then cleared using toluene ( $\sim 5 \mathrm{~mL}$; Prolabo) and mounted on carefully cleaned

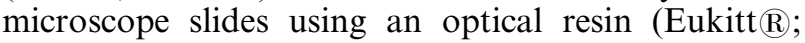
Serlabo, Paris, France). Slides were examined by light microscopy $(\times 160$ magnification $)$.

The result was considered to be positive when the whole sample contained one or more typical ferruginous bodies, as defined by CHURG and WARNOCK [4], as this finding is suggestive of significant asbestos lung retention [5-7].

\section{Asbestos exposure assessment}

The occupational exposure of the subjects was analysed in collaboration with the company's medical department. The duration of occupational exposure to asbestos and the start and end dates of exposure were known for each subject. An intensity of exposure was defined for each job position based on dust measurements performed in numerous points of the workshops: 1) atmospheric measurements determined by Casella pumps on a membrane filter have been available since 1973: phase-contrast light microscopy counts of fibres $(>5 \mu \mathrm{m}$ in length, $<3 \mu \mathrm{m}$ in diameter and with a length/diameter ratio $>3$ ), were expressed in fibres $\cdot \mathrm{mL}^{-1}$. These measurements were performed by an accredited laboratory participating in comparison protocols with other specialised laboratories; 2) between 1960-1974, samples were collected on soluble filters by an Avy-Raillère-Martin (ARM) type of apparatus, and the light microscopy fibre counts were expressed as particles per litre of air. Measurements were performed by a specialised laboratory independent of the company; 3 ) no atmospheric measurements were available for the period before 1960. However, a general exposure model for each job position was developed by applying coefficients, based on production reports derived from the company's archives and testimonies from retired executives, to the first atmospheric data available. Thus, before 1939, exposures were evaluated to be $50 \%$ of those observed in 1960. For the period 1939-1945, characterised by suspension of the production of asbestos products, a residual mean level of 5 fibres $\cdot \mathrm{mL}^{-1}$ was adopted for all production positions due to residual contamination of the workshop. For the period 19451960, a linear extrapolation was established between the 1945 levels and the 1960 levels.

Comparison of the results provided by the two methods (Casella and ARM), applied simultaneously during 1974, demonstrated a significant linear relationship between the two sampling techniques ( $\mathrm{r}=0.81$, $\mathrm{p}=0.0001)$. This relationship was used to estimate the conversion factor allowing expression in fibres $\cdot \mathrm{mL}^{-1}$ of those measurements previously evaluated in particles per liter of air. This factor was equal to $2 \times 10^{-4}$ (1 fibre $\cdot \mathrm{mL}^{-1}=2 \times 10^{-4}$ particles $\cdot \mathrm{L}^{-1}$ ).

This method allowed evaluation of the variations in the degree of exposure to asbestos for each of the company's job positions.

Thus, around the years 1960-1970, atmospheric exposure levels $\leqslant 10$ fibres $\cdot \mathrm{mL}^{-1}$ were observed in friction material wokshops, while levels up to $>100$ fibres $\cdot \mathrm{mL}^{-1}$ were observed in textile workshops.

A cumulative exposure index, expressed in fibres. $\mathrm{mL}^{-1} \times \mathrm{yrs}$, was therefore calculated for each subject by determining the sum of the products (exposure $\times$ duration) characterising each job position.

The asbestos exposure parameters evaluated in this study were: duration of exposure, cumulative exposure index, intensity of exposure (cumulative index divided by duration of exposure), latency (time since onset of exposure), type of asbestos handled (chrysotile alone, or mixed (chrysotile associated with crocidolite)). The subject's sex, age, smoking status and the time since retirement were also taken into account.

\section{Statistical methods}

The association between the presence of asbestos bodies in the sputum and each of the predictor variables was first assessed with univariate logistic regression 
models. All continuous variables were transformed into categorical data because the assumption of linearity in the logit was not verified. For each continuous variable, the choice of cut-off values was guided by the curve relating the prevalence of asbestos bodies to the considered variable. Relative risks and 95\% confidence intervals are presented. Odds ratios were also calculated to allow comparison with the results of the multivariate analysis (note that odds ratio values are not good estimations of relative risks because the presence of asbestos bodies in sputum cannot be considered to be rare in this study population).

A multiple logistic regression model was then applied in order to isolate the effect of each factor adjusted for all other factors. To avoid numerical problems created by multicollinearity, explanatory variables too highly correlated among themselves were not included at the same time in the same model. Different models were tested according to the relationships examined. Variables associated with asbestos bodies at a level of $p<0.20$ on univariate analysis and smoking habits were included in the multivariate analysis. Adjusted odds ratios with $95 \%$ confidence limits are presented. Statistical significance was defined as $\mathrm{p}<0.05$.

\section{Results}

\section{Population and exposure data}

The characteristics of the population and occupational asbestos exposure data for the subjects of this population are presented in table 1. These retired subjects had a high cumulative exposure to asbestos (an average of 217 fibres $\cdot \mathrm{mL}^{-1} \times \mathrm{yr}$ ). Females, predominantly employed in the textile industry, had an exposure usually comprising of crocidolite.

\section{Sputum data}

Among the 270 retired workers, when the sputum contained neither macrophages nor asbestos bodies, which occurred in 47 cases $(17.4 \%)$, there was a high probability that it actually corresponded to a simple saliva sample, and the sample could not be considered to be representative of the lung compartment. The sputum could be considered as definitely being derived from the lung in the following cases: when it contained either only macrophages without asbestos bodies (105 cases out of 270), when it contained only asbestos bodies without macrophages (21 out of 270 ), or when it contained both macrophages and asbestos bodies (97 out of 270); this occurred in 223 cases out of 270 $(82.6 \%)$.

Sputum contained at least one asbestos body in 118 subjects, corresponding to $53 \%$ of samples derived from the lung (118 out of 223).

Table 2 shows that the lung origin of the sputum was not related to: either sex or smoking; the type of asbestos handled; or the subject's age; or the time since retirement. In contrast, the time since onset of exposure was significantly longer in subjects expressing lung sputum and a similar relationship, close to statistical significance, was observed for the duration of asbestos exposure, cumulative exposure index and intensity of exposure.

The relationships between the presence of asbestos bodies in the sputum and individual parameters (sex, age and exposure parameters) were analysed on the population of subjects who produced sputum samples of confirmed lung origin $(n=223)$, firstly by univariate analysis and then by multivariate analysis.

Table 3 presents the results of univariate analysis. The presence of asbestos bodies in the sputum did not appear to be significantly related to either sex or smoking status. In contrast, it was more frequent when the asbestos exposure included crocidolite and was increasingly frequent with increasing age, time since retirement, cumulative exposure index, duration of exposure, intensity of exposure and latency since the onset of exposure.

The results of multivariate analysis are shown in table 4. The sex variable was not included in this analysis ( $\mathrm{p}=0.48$ on univariate analysis). As several

Table 1.-Sex, age, smoking status and occupational asbestos exposure of subjects

\begin{tabular}{|c|c|c|c|c|}
\hline & All subjects & Males & Females & p-value \\
\hline Subjects n & 282 & 222 & 60 & \\
\hline Age yrs & $65 \pm 5(55-83)$ & $65 \pm 5(55-83)$ & $64 \pm 4(56-78)$ & NS \\
\hline \multicolumn{5}{|l|}{ Smoking status } \\
\hline Nonsmokers & $119(42.2)$ & $63(28.4)$ & $56(93.3)$ & \\
\hline Exsmokers & 129 (45.7) & $126(56.8)$ & $3(5.0)$ & \\
\hline Current smokers & $34(12.1)$ & $33(14.9)$ & $1(1.7)$ & $* * *$ \\
\hline Time since retirement yrs & $8.0 \pm 3.8(1-20)$ & $8.0 \pm 3.9(1-20)$ & $8.1 \pm 3.6(1-16)$ & NS \\
\hline \multicolumn{5}{|c|}{ Mineralogical type of asbestos } \\
\hline Chrysotile & $182(64.5)$ & 164 (73.9) & $18(30.0)$ & \\
\hline Chrysotile+crocidolite & $100(35.5)$ & $58(26.1)$ & $42(70.0)$ & **** \\
\hline Duration of exposure yrs & $24.1 \pm 7.5(4-48)$ & $24.0 \pm 7.0(8-45)$ & $24.7 \pm 9.2(4-48)$ & NS \\
\hline $\begin{array}{l}\text { Cumulative exposure } \\
\text { fibres } \cdot \mathrm{mL}^{-1} \times \mathrm{yrs}\end{array}$ & $217 \pm 156.4(4.3-698.3)$ & $210.2 \pm 152.3(5.5-698.3)$ & $242.1 \pm 169.7(4.3-638.1)$ & NS \\
\hline $\begin{array}{l}\text { Exposure intensity } \\
\text { fibres } \cdot \mathrm{mL}^{-1}\end{array}$ & $8.7 \pm 5.0(0.3-24.9)$ & $8.3 \pm 4.7(0.3-24.9)$ & $10.0 \pm 5.8(0.3-22.0)$ & NS \\
\hline $\begin{array}{l}\text { Latency yrs since } \\
\text { onset of exposure }\end{array}$ & $32.9 \pm 7.7(15-64)$ & $32.6 \pm 7.3(16-55)$ & $34.0 \pm 9.0(15-64)$ & NS \\
\hline
\end{tabular}

Data are presented as mean $\pm \mathrm{SD}$ (minimum-maximum) or $\mathrm{n}(\%)$. NS: nonsignificant. ${ }^{* * *}: \mathrm{p}<0.001$. 
Table 2. - Ability to produce a sputum sample of lung origin, according to sex, age and exposure determinants

\begin{tabular}{|c|c|c|c|}
\hline & \multicolumn{2}{|c|}{ Sputum derived from lung } & \multirow[t]{2}{*}{ p-value } \\
\hline & No & Yes & \\
\hline Subjects n & 47 & 223 & \\
\hline \multicolumn{4}{|l|}{ Sex } \\
\hline Males & $36(76.6)$ & 177 (79.4) & \\
\hline Females & $11(23.4)$ & $46(20.6)$ & NS \\
\hline \multicolumn{4}{|l|}{ Smoking status } \\
\hline Current smokers & $5(10.6)$ & $26(11.7)$ & \\
\hline Exsmokers & $16(34)$ & $110(49.3)$ & \\
\hline Nonsmokers & $26(55.3)$ & $87(39.0)$ & NS \\
\hline \multicolumn{4}{|l|}{ Mineralogical } \\
\hline type of asbestos & & & \\
\hline Chrysotile & $32(68.1)$ & $136(61.0)$ & \\
\hline Chrysotile+crocidolite & $15(31.9)$ & $87(39.0)$ & NS \\
\hline Age yrs & $64.0 \pm 4.4(57-73)$ & $64.6 \pm 5.3(55-83)$ & NS \\
\hline $\begin{array}{l}\text { Time since } \\
\text { retirement yrs }\end{array}$ & $7.5 \pm 3.3(2-13)$ & $8.1 \pm 3.9(1-20)$ & NS \\
\hline $\begin{array}{l}\text { Duration of } \\
\text { exposure yrs }\end{array}$ & $22.4 \pm 6.8(9-36)$ & $24.6 \pm 7.5(4-48)$ & 0.06 \\
\hline $\begin{array}{l}\text { Cumulative exposure } \\
\text { fibres } \cdot \mathrm{mL}^{-1} \times \mathrm{yrs}\end{array}$ & $177.0 \pm 133.4(4.3-546.5)$ & $224.1 \pm 157.9(5.5-698.3)$ & 0.06 \\
\hline $\begin{array}{l}\text { Exposure intensity } \\
\text { fibres } \cdot \mathrm{mL}^{-1}\end{array}$ & $7.4 \pm 4.4(0.3-18.2)$ & $8.9 \pm 5.1(0.3-24.9)$ & 0.07 \\
\hline $\begin{array}{l}\text { Latency yrs since } \\
\text { onset of exposure }\end{array}$ & $31.0 \pm 7.9(19-48)$ & $33.4 \pm 7.5(15-64)$ & 0.05 \\
\hline
\end{tabular}

Data are presented as mean \pm SEM (minimum-maximum) or n (\%). NS: nonsignificant.

predictive variables were strongly correlated with each other (age with time since retirement, cumulative exposure index with duration of exposure, duration of exposure with latency), several models were studied. Multivariate analysis confirmed the results of univariate analysis, except for latency, which was no longer significantly related to the presence of asbestos bodies in the sputum $(\mathrm{p}=0.09)$.

\section{Discussion}

\section{Sputum collection procedures}

Although hypertonic saline nebulisation has been shown to improve the efficacy of sputum collection without affecting the cell content of the sample [8], isotonic saline ultrasonic nebulisation was chosen, which proved to be a very safe technique in the subjects of this population whose ages ranged from 55-83 yrs.

However, lung origin of the sputum was frequent in this study, whereas $75 \%$ of sputum samples (202 out of 270) contained macrophages. This rate is not very different from the rates reported in younger subjects by SÉBASTIEN et al. [9] and MACDONALD et al. [10]: 49\% and $63 \%$ of sputa containing macrophages, respectively. However, these authors did not use nebulisation and physiotherapy to collect sputum.

Mineralogical examination of the sputum must be combined with cytological examination looking for the presence of macrophages to confirm the lung origin of the sputum.

The subjects' sex and smoking status were not significantly correlated with the quality of sputum in this series.

Mineralogical sputum examination: sensitivity and specificity

The presence of asbestos bodies was observed in only $53 \%$ of lung sputa in this group of retired subjects with known high exposures to asbestos, exceeding an average of $200 \mathrm{fibres} \cdot \mathrm{mL}^{-1} \times \mathrm{yrs}$.

In previous reports, the frequency of detection of asbestos bodies in sputum differed from one occupational cohort to another: in highly exposed subjects, FARLEY et al. [11] and MACDONALD et al. [10] reported $35 \%$ and $29 \%$ of positive analyses, respectively. In vermiculite miners, SEBASTIEN et al. [9] detected asbestos bodies in the sputum of $75 \%$ of workers; TESCHLER et al. [3] reported positive asbestos body counts in $36.5 \%$ of occupationally exposed subjects and Sulotto et al. [12] reported a rate of $44.4 \%$.

This confirms the poor sensitivity of mineralogical sputum examination, and is particularly emphasised by TESCHLER et al. [3], who observed the absence of asbestos bodies in sputum in one-third of heavily exposed subjects, despite a significant asbestos body content on bronchoalveolar lavage.

It is clear that a negative mineralogical sputum examination cannot therefore, exclude the reality of even high occupational exposure. Multiple sputum samples would increase the odds of a positive result [12].

Conversely, the specificity of this examination has been largely confirmed [3, 10, 13] either by: 1) comparison of mineralogical sputum analysis with 
Table 3.-Presence of asbestos bodies in sputum according to sex, age, smoking habits and occupational asbestos exposure (univariate analysis)

\begin{tabular}{|c|c|c|c|c|c|c|}
\hline & \multirow[t]{2}{*}{ Subjects $\mathrm{n}$} & \multicolumn{5}{|c|}{ Presence of asbestos bodies in sputum } \\
\hline & & $\%$ & p-value & $\mathrm{RR}$ & $95 \% \mathrm{CI}$ & OR \\
\hline \multicolumn{7}{|l|}{ Sex } \\
\hline Males & 177 & 51.4 & & 1 & & 1 \\
\hline Females & 46 & 58.7 & NS & 1.1 & $0.9-1.5$ & 1.3 \\
\hline \multicolumn{7}{|l|}{ Age yrs } \\
\hline $55-60$ & 48 & 37.5 & & 1 & & 1 \\
\hline $61-67$ & 115 & 48.7 & & 1.3 & $0.9-2.0$ & 1.6 \\
\hline$\geqslant 68$ & 60 & 73.3 & $* * *$ & 2.0 & $1.3-2.9$ & 4.6 \\
\hline \multicolumn{7}{|l|}{ Smoking status } \\
\hline Nonsmokers & 87 & 54.0 & & 1 & & 1 \\
\hline Smokers+exsmokers & 136 & 52.2 & NS & 1.0 & $0.7-1.2$ & 0.9 \\
\hline \multicolumn{7}{|l|}{ Time since retirement yrs } \\
\hline $1-6$ & 90 & 41.1 & & 1 & & 1 \\
\hline $7-11$ & 88 & 54.5 & & 1.3 & $1.0-1.8$ & 1.7 \\
\hline$\geqslant 12$ & 45 & 73.3 & ** & 1.8 & $1.3-2.4$ & 3.9 \\
\hline \multicolumn{7}{|c|}{ Mineralogical type of asbestos } \\
\hline Chrysotile & 136 & 37.5 & & 1 & & 1 \\
\hline Chrysotile+crocidolite & 87 & 77.0 & $* * *$ & 2.1 & $1.6-2.6$ & 5.6 \\
\hline \multicolumn{7}{|c|}{ Cumulative exposure fibres $\cdot \mathrm{mL}^{-1} \times \mathrm{yrs}$} \\
\hline $0-200$ & 125 & 37.6 & & 1 & & 1 \\
\hline $200-400$ & 58 & 62.1 & & 1.7 & $1.2-2.2$ & 2.7 \\
\hline$>400$ & 40 & 87.5 & $* * *$ & 2.3 & $1.8-3.0$ & 11.6 \\
\hline \multicolumn{7}{|l|}{ Duration of exposure yrs } \\
\hline$<25$ & 115 & 40.9 & & 1 & & 1 \\
\hline$\geqslant 25$ & 108 & 65.7 & $* * *$ & 1.6 & $1.2-2.1$ & 2.8 \\
\hline \multicolumn{7}{|c|}{ Exposure intensity fibres $\cdot \mathrm{mL}^{-1}$} \\
\hline $0-8$ & 112 & 34.8 & & 1 & & 1 \\
\hline $8-12$ & 53 & 64.2 & & 1.8 & $1.3-2.6$ & 3.3 \\
\hline$>12$ & 58 & 77.6 & $* * *$ & 2.2 & $1.7-3.0$ & 6.5 \\
\hline \multicolumn{7}{|c|}{ Latency yrs since onset of exposure } \\
\hline $15-30$ & 72 & 33.3 & & 1 & & 1 \\
\hline $31-39$ & 106 & 57.5 & & 1.7 & $1.2-2.5$ & 2.7 \\
\hline$\geqslant 40$ & 45 & 73.3 & $* * *$ & 2.2 & $1.5-3.2$ & 5.5 \\
\hline
\end{tabular}

RR: relative risk; 95\% CI: 95\% confidence interval; OR: odds ratio; NS: nonsignificant. $* *: \mathrm{p}<0.01 ; * * *: \mathrm{p}<0.001$.

other biometrological approaches, for example, a good correlation has been demonstrated between the presence or number of asbestos bodies in the sputum and the lung asbestos body content $[3,5,14]$. Mineralogical sputum data and bronchoalveolar lavage asbestos body concentration appear to be less closely related, but TESCHLER et al. [3] did not find any positive sputa when bronchoalveolar lavage was negative; or 2) by the concordance between the presence of asbestos bodies in the sputum and the existence of radiological signs of pleural or pulmonary fibrosis [9, 15].

Factors related to the presence of asbestos bodies in the sputum

Asbestos-exposure level. A significant relationship between the presence of asbestos bodies in the sputum and occupational asbestos exposure data, as shown in this study, appears to be inconsistently reported in the literature: absent in some studies [5, 15] and present in others $[3,16]$. However, in these publications, determination of occupational asbestos exposure was not based on workshop atmospheric dust measurements, as in the present study.
Mineralogical type of asbestos fibres. The particular propensity of amphibole asbestos to form asbestos bodies has already been emphasised by various authors $[17,18]$, and this is in line with the relationship observed in this study between the presence of asbestos bodies in sputum and a history of exposure to crocidolite. SulotTo et al. [12], however, did not report such a relationship.

It is noteworthy that among the retired workers exposed to chrysotile only, $37 \%$ had asbestos bodies in the sputum. It is unlikely to be due to crocidolite exposure, because crocidolite was only present in textile processing, which took place in independent workshops. Complementary analysis using transmission electron microscopy (TEM) on several samples exhibiting high levels of asbestos bodies revealed that all asbestos bodies were formed on amphibole fibres in textile workers, mainly amosite and crocidolite. The exact nature of the core of asbestos bodies could not be determined in the few samples from friction workers which could be analysed with TEM. Although no tremolite fibre was observed in these samples, the fact that these asbestos bodies could be formed on amphibole fibres (especially tremolite contaminating chrysotile) cannot be ruled out. 
Table 4.-Presence of asbestos bodies in sputum according to sex, age, smoking habits and occupational asbestos exposure (multivariate analysis)

\begin{tabular}{|c|c|c|c|c|}
\hline & $\underset{\mathrm{n}}{\text { Subjects }}$ & p-value & $\begin{array}{l}\text { Adjusted } \\
\text { OR }\end{array}$ & $\begin{array}{c}95 \% \\
\text { CI }\end{array}$ \\
\hline \multicolumn{5}{|l|}{ Age yrs ${ }^{\#}$} \\
\hline $55-60$ & 48 & & 1 & \\
\hline $61-67$ & 115 & & 1.2 & $0.5-2.8$ \\
\hline$\geqslant 68$ & 60 & $* * *$ & 5.9 & $2.3-15.0$ \\
\hline \multicolumn{5}{|l|}{ Smoking status } \\
\hline Nonsmokers & 87 & & 1 & \\
\hline $\begin{array}{l}\text { Smokers+ } \\
\text { exsmokers }\end{array}$ & 136 & NS & 1.2 & $0.6-2.4$ \\
\hline \multicolumn{5}{|l|}{$\begin{array}{l}\text { Time since } \\
\text { retirement }\end{array}$} \\
\hline $1-6$ & 90 & & 1 & \\
\hline $7-11$ & 88 & & 2.0 & $1.0-4.1$ \\
\hline$\geqslant 12$ & 45 & $* * *$ & 6.5 & $2.6-15.9$ \\
\hline \multicolumn{5}{|c|}{$\begin{array}{l}\text { Mineralogical type } \\
\text { of asbestos }\end{array}$} \\
\hline Chrysotile & 136 & & 1 & \\
\hline $\begin{array}{l}\text { Chrysotile+ } \\
\text { crocidolite }\end{array}$ & 87 & $* * *$ & 5.1 & $2.5-10.4$ \\
\hline \multicolumn{5}{|c|}{$\begin{array}{l}\text { Cumulative exposure } \\
\text { fibres } \cdot \mathrm{mL}^{-1} \times \mathrm{yrs}\end{array}$} \\
\hline $0-200$ & 125 & & 1 & \\
\hline $200-400$ & 58 & & 2.1 & $1.0-4.3$ \\
\hline$>400$ & 40 & $* * *$ & 9.1 & $3.1-26.8$ \\
\hline \multicolumn{5}{|l|}{$\begin{array}{l}\text { Duration of } \\
\text { exposure }^{+} \text {yrs }\end{array}$} \\
\hline$<25$ & 115 & & 1 & \\
\hline$\geqslant 25$ & 108 & ** & 2.4 & $1.2-4.8$ \\
\hline \multicolumn{5}{|c|}{$\begin{array}{l}\text { Exposure intensity } \\
\text { fibres } \cdot \mathrm{mL}^{-1}\end{array}$} \\
\hline $0-8$ & 112 & & 1 & \\
\hline $8-12$ & 53 & & 2.4 & $1.1-5.0$ \\
\hline$>12$ & 58 & * & 2.8 & $1.2-6.6$ \\
\hline \multicolumn{5}{|c|}{$\begin{array}{l}\text { Latency yrs since } \\
\text { onset of exposure }\end{array}$} \\
\hline $15-30$ & 72 & & 1 & \\
\hline $31-39$ & 106 & & 1.5 & $0.7-3.2$ \\
\hline$\geqslant 40$ & 45 & NS & 2.9 & $1.1-7.3$ \\
\hline
\end{tabular}

OR: odds ratio; 95\% CI: 95\% confidence interval. ${ }^{*}$ : model including the following variables: mineralogical type of asbestos, cumulative exposure, smoking status and age; : model including the following variables: mineralogical type of asbestos, cumulative exposure, smoking status and time since retirement; ${ }^{+}$: model including the following variables: mineralogical type of asbestos, exposure duration and intensity, smoking status and age; \$: model including the following variables: mineralogical type of asbestos, latency, exposure intensity, smoking status and age. *: $\mathrm{p}<0.05$; **: $\mathrm{p}<0.01 ; * * *: \mathrm{p}<0.001$; NS: nonsignificant.

Tobacco smoking. Although some studies report a positive relationship $[3,9,15]$ between smoking and the presence of asbestos bodies in sputum, no significant relationship was demonstrated in this study, which confirms the results reported by SCANSETTI et al. [19].

Time since cessation of exposure. TESCHLER et al. [3] reported a negative correlation between time since cessation of exposure and the number of asbestos bodies in the sputum, while other studies $[10,15]$ did not report any significant relationship between this time interval and the presence of asbestos bodies in the sputum. The positive correlation observed in the present study between the presence of asbestos bodies in the sputum and the time since retirement is somewhat surprising and suggests the possibility of increased fibre excretion in older subjects.

\section{Conclusion}

In conclusion, this study shows that sputum analysis for asbestos bodies is a noninvasive examination, which can be proposed even in retired subjects.

The presence of asbestos bodies in the sputum is correlated with the intensity of asbestos exposure and can reflect occupational contact with asbestos, even when it has been stopped for many years. Conversely the sputum examination is often negative, even in subjects with a history of heavy asbestos exposure, and only positive results must therefore be taken into account. Nevertheless sputum analysis for asbestos bodies may contribute to the identification of subjects at high risk of lung cancer, who could be included in screening programmes currently under evaluation.

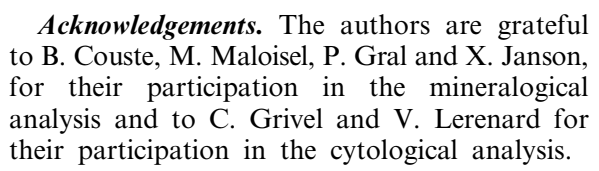

References

1. Sone S, Takashima S, Li F, et al. Mass screening for lung cancer with mobile spiral computed tomography scanner. Lancet 1998; 351: 1242-1245.

2. Henschke CI, MacCauley DI, Yankelevitz DF, et al. Early Lung Cancer Action Project: overall design and findings from baseline screening. Lancet 1999; 354: 99 105 .

3. Teschler H, Thompson AB, Dollenkamp R, Konietzko N, Costabel U. Relevance of asbestos bodies in sputum. Eur Respir $J$ 1996; 9: 680-686.

4. Churg A, Warnock ML. Asbestos and other ferruginous bodies. Am J Pathol 1981; 102: 447-456.

5. Roggli VL, Greenberg SD, McLarty JW, et al. Comparison of sputum and lung asbestos body counts in former asbestos workers. Am Rev Respir Dis 1980; 122: 941-945.

6. Sebastien P, Awad L, Bignon J, Petit G, Barris YI. Ferruginous bodies in sputum as an indication of exposure to airborne mineral fibers in the mesothelioma villages of Cappadocia. Arch Environ Health 1984; 39: 18-23.

7. Roggli VL, McLarty JW, Greenberg SD. A B in sputum: a clinical marker of exposure. J Occup Med 1983; 25: 508

8. Popov TA, Pizzichini MM, Pizzichini E, et al. Some technical factors influencing the induction of sputum for cell analysis. Eur Respir J 1995; 8: 559565 .

9. Sebastien $\mathrm{P}$, Armstrong $\mathrm{B}$, Case B, Barwick $\mathrm{H}$, Keskula H, Mc Donald JC. Estimation of amphibole exposure from asbestos body and macrophage counts 
in sputum. A survey in vermiculite miners. Ann Occup Hyg 1988; 32: Suppl. 1, 195-201.

10. McDonald JC, Sebastien P, Case B, McDonald AD, Dufresne A. Ferruginous body counts in sputum as an index of past exposure to mineral fibres. Ann Occup Hyg 1992; 36: 271-282.

11. Farley ML, Greenberg SD, Shuford EH Jr, Hurst GA, Spivey CG, Christianson CS. Ferruginous bodies in sputa of former asbestos workers. Acta Cytol 1977; 21: 693-700.

12. Sulotto F, Capellaro E, Chiesa A, Villari S, Bontempi S, Scansetti G. Relationship between asbestos bodies in sputum and the number of specimens. Scand $J$ Work Environ Health 1997; 23: 48-53.

13. Wheeler TM, Johnson EH, Coughlin D, Greenberg SD. The sensitivity of detection of asbestos bodies in sputa and bronchial washings. Acta Cytol 1988; 32: 647-650.

14. Bignon J, Depierre A, Bonnaud G, Goni J, Brouet G. Demonstration of ferruginous bodies by microfiltration of the sputum. Correlation with the asbestosis risk. Nouv Presse Med 1973; 2: 1697-700.

15. McLarty JW, Greenberg SD, Hurst GA, et al. The clinical significance of ferruginous bodies in sputa. J Occup Med 1980; 22: 92-96.

16. Greenberg SD, Hurst GA, Christianson SC, Matlage WJ, Hurst IG, Mabry LC. Pulmonary cytopathology of former asbestos workers. Report of the first year. Am J Clin Pathol 1976; 66: 815-822.

17. Roggli VL. Asbestos bodies and nonasbestos ferruginous bodies. In: Roggli VL, Greenberg D, Pratt PC, eds. Pathology of Asbestos-Associated Diseases. Boston, Little, Brown and Company, 1992; pp. 39-75.

18. Churg A. Nonneoplastic disease caused by asbestos. In: Churg A, Green FHY, eds. Pathology of occupational lung disease. Baltimore USA, Williams \& Wilkins, 1997; pp. 277-338.

19. Scansetti G, Chiesa A, Capellaro E, Villari S, Sulotto F. Asbestos bodies in sputum of asbestos exposed workers. Med Lav 1996; 87: 283-288. 